Vastyanov R. S., Yermuraki P. P., Stoyanov A. N., Tiron O. I., Beseda Ya. V., Ostapenko I. O., Dobrovolsky V. V., Lapshin D. Ye., Stecenko A. V. New aspects of pedagogical activity in the distant form of pathological physiology teaching to medical university students. Journal of Education, Health and Sport. 2021;11(10):173-186. eISSN 2391-8306. DOI http://dx.doi.org/10.12775/JEHS.2021.11.10.015

https://apcz.umk.pl/JEHS/article/view/JEHS.2021.11.10.015

https://zenodo.org/record/5590164

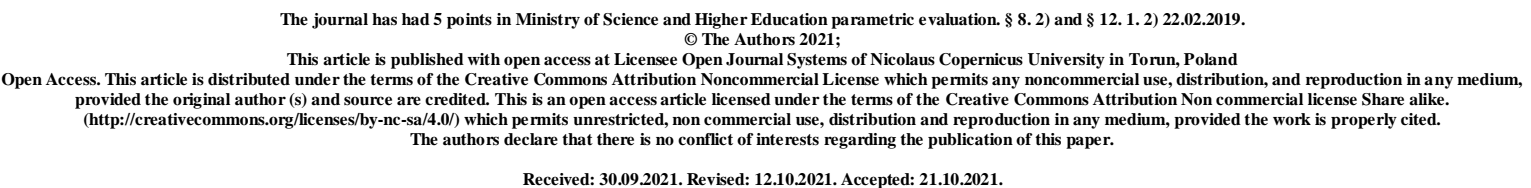

UDK 378.147:616-092+616.35:378.147:336.733+614.252.2:617

\title{
NEW ASPECTS OF PEDAGOGICAL ACTIVITY IN THE DISTANT FORM OF PATHOLOGICAL PHYSIOLOGY TEACHING TO MEDICAL UNIVERSITY STUDENTS
}

\author{
R. S. Vastyanov, P. P. Yermuraki, A. N. Stoyanov, O. I. Tiron, Ya. V. Beseda, \\ I. O. Ostapenko, V. V. Dobrovolsky, D. Ye. Lapshin, A. V. Stecenko
}

\section{Odessa National Medical University, Odessa, Ukraine}

\begin{abstract}
Distance learning (DL) is a completely new and unique form of education, which got forced to switch to by the current pandemic of coronavirus disease.

Note that until now, distance learning technologies have been used at the department of general and clinical pathological physiology and some other departments of the Odessa National Medical University (ONMedU).

The aim of this analytical article is to analyze the efficacy of ONMedU General and Clinical Pathological Physiology Department staff during the one and a half year period of the coronavirus infection pandemic with an accent to psychological approach to students modified teaching. The urgent need of time and the primary desire to protect students and their own lives during 2020-2021 requires us to improve our own pedagogical approaches in the further on-line teaching of students.
\end{abstract}


We see success in systematic methodological work with students, the implementation of which will make it possible to evoke and increase their motivation to study histology. The importance of this methodological technique, supported in the senior years of medical universities by the integration of teaching theoretical and clinical disciplines, the approximation of teaching to specific clinical cases will help optimize the assimilation of morphological knowledge by students at least and, undoubtedly, in the near future will lead to a better assimilation of clinical disciplines.

In connection with the ideas of individualized and developmental learning, the use of psychological capabilities of learning tools in the virtual environment brings both pedagogy and psychology to a new level of understanding the mediation of mental, creative, communicative and executive learning and learning activities.

The use of distance learning helps the students to acquire skills of independent work, creates comfortable conditions for creativity, increases the creative and intellectual potential of the student through self-organization, the ability to interact with computer technology and make responsible decisions, creates favorable conditions for individual creative expression in the process of learning, for the development of the student's personality.

The authors are convinced that the optimization and improvement of the educational process in medical universities is to draw students' attention to the problems that the medical community is dealing with on a daily basis today.

Key words: distant teaching; pathological physiology; neuroscience; morphology; comorbidity; efficacy of teaching

Introduction. Distance learning (DL) is a completely new and unique form of education, which got forced to switch to by the current pandemic of coronavirus disease.

Note that until now, distance learning technologies have been used at the department of general and clinical pathological physiology and some other departments of the Odessa National Medical University (ONMedU). In the search aspects, together with colleagues, we developed theoretical prerequisites for the effective use of distance learning in the medical education system $[9,10]$.

In the articles and monographs of modern authors dealing with the problems and study of distance education in our country, there are certain contradictions, because each of them, before starting to understand the problem, comprehensively researched the feasibility and effectiveness of such education on our personal experience [5-7]. 
Initially, we were driven by two main tasks that were urgently needed to get implemented in our daily activities in order to increase the effectiveness of the students' assimilation of the course of pathophysiology: (a) assimilation of the necessary educational material in the process pf a lecture course and a cycle of practical communication classes and (b) maintaining the continuity of biomedical disciplines while presenting material to the students in pathophysiology classes.

We also note that during the first weeks of distance pedagogical work with students, the concept of the need to analyze the effectiveness of the psychological component of teaching our discipline got clearly formulated.

Thus, the aim of this analytical article is to analyze the efficacy of ONMedU General and Clinical Pathological Physiology Department staff during the one and a half year period of the coronavirus infection pandemic with an accent to psychological approach to students modified teaching.

When critically analyzing the results achieved with distance learning, we are aware of its objective shortcomings for training highly qualified medical specialists, since online electronic technologies, despite the seeming ease of communication, still contribute to significant difficulties in the formation of communicative and practice-oriented competencies among medical students of initial courses. The urgent need of time and the primary desire to protect students and their own lives during 2020-2021 requires us to improve our own pedagogical approaches in the further on-line teaching of students. In this regard, we present our views on the above problematic points.

1. Actualization of maintaining continuity in the presentation of biomedical disciplines in the study of pathological physiology.

It is important to increase the intellectual, scientific, educational, professionallyoriented level of future doctors, providing them with modern, more effective innovative and informational medical technologies. The methodological aspects of teaching medical disciplines, taking, for example, morphological subjects (especially, histology and cytology), in our opinion, are very important.

The first aspect: we are confident that there is the need to focus the attention of students on the consistency and continuity of the study of medical disciplines and the acquisition of relevant knowledge and competencies. At the same time, a clear understanding and orientation in morphological knowledge makes it much easier for students to master such fundamental disciplines as biochemistry, pathological anatomy, pathological physiology, etc. 
In this regard, we note the extreme inferiority, inconsistency and narrowness of the medical outlook with a lack of understanding of the simplest pathomorphological changes in patients with various kinds of pathological processes of inflammatory, degenerative, traumatic, infectious, tumor genesis....

We are sure that only a full understanding of the logical chains of ideas of students, interns (later and doctors of various profiles) in the direction of: composition $\rightarrow$ structure $\rightarrow$ function $\rightarrow$ structural and functional integration (interaction) of organs and systems is critically important for a correct understanding of dysfunctional disorders of integration and regulatory mechanisms in pathology [12]. Indeed, a clear understanding of the Virchow triad in maintaining the homeostatic constants of the body guarantees the doctor an adequate implementation of the clinical and laboratory triad: early and correct diagnosis of a specific pathological process, its pathogenetically substantiated complex pharmacological correction and a recovery and/or rehabilitation period, the successful result of which will be the activation of sanogenic mechanisms, including normalization of morphological criteria of cellular activity in particular.

Also, there is the second aspect, which allows us to dwell on our many years of experience in teaching histology. We are confident in the critical importance of the motivational component of teaching histology. Its formation is an important pedagogical problem, since it is incredibly difficult to force a student to learn the material if he himself does not understand why he needs it.

Increasing the motivation of medical students means providing the state with future highly qualified doctors who will save millions of lives in the future.

As it is known, students' positive motivational excitement to the learning process is determined by the following:

a) awareness of the immediate and final goals of learning;

b) awareness of the theoretical and practical significance of knowledge;

c) an emotional form of presentation of educational material;

d) demonstration of "promising lines" in the development of scientific concepts;

e) professional orientation of educational activities;

f) the creation of tasks and questions that create problem situations in the structure of educational activities;

g) cultivation of curiosity and "cognitive psychological climate" in the study group [1]. 
We are confident that such an integrated approach to the implementation of all these factors creates and increases motivation among students, directly affects the creation of a holistic picture of the future profession among students, emphasizes the dominant role of medicine in the harmonious development of society, as well as the importance of the students of medical universities in their own eyes. The latter is no less important, because we are talking about young people for whom their image in the eyes of friends and peers is almost in the first place.

The above has been implemented in the work of the department of histology, cytology and embryology of the Odessa National Medical University and has been successfully used by our team over the past 20 years with an annual analysis of its effectiveness. During the last academic year, complicated by the coronavirus pandemic, the teachers of the department improved the method of remote lecturing and practical exercises with maximum involvement in the intensive intellectual process of students by including multimedia lectures with slides illustrating micrographs of the cell structure in the teaching process, as well as interactive programs. For example, it was made easier for students to perceive the conduction of an electrical impulse through the layers of the retina. It is not interesting to learn (read, cram) only that which the student does not understand at all (the mistake of the previous system of teaching histology). With the advent of understanding, there is desire, enthusiasm and, of course motivation.

Summing up, we note that we have developed and introduced a complex of methodological techniques into the pedagogical work, within the framework of which all the components of the implementation of the motivational component of students got implemented. In this way, we make it easier for students to study at other departments of the medical university, because the hierarchical system that got demonstrated to them, is based on the formation of a conditioned reflex of cognition and the acquisition of new competencies, and subsequently only strengthens and finds new positive effects of reinforcement at other departments of the university $[11,14]$.

We are confident that such an integrated approach, covering all aspects of student life, can evoke a response in the minds of the younger generation. Students realize who they are going to become, begin to see the perspective. It is important that they grasp and subsequently clearly realize the importance of understanding the structural and functional unity of organs and systems of the body for the formation of a highly qualified specialist. Students are interested, because the symbiosis of reason and emotions makes them go further and further in the development of new histological knowledge. They understand the theoretical (in the $2^{\text {nd }}$ 
year) and practical (in the 6th year) value of the knowledge gained, they are aware of the near and final prospects.

Consequently, we see success in systematic methodological work with students, the implementation of which will make it possible to evoke and increase their motivation to study histology. The importance of this methodological technique, supported in the senior years of medical universities by the integration of teaching theoretical and clinical disciplines, the approximation of teaching to specific clinical cases will help optimize the assimilation of morphological knowledge by students at least and, undoubtedly, in the near future will lead to a better assimilation of clinical disciplines.

2. Application of the psychological approach in distance work with students: disadvantages and ways to overcome them.

The urgency of the problem of psychological aspects of learning in a virtual environment is dictated by the need to develop skills of independent learning and research creative approaches to the learning process, the formation of critical thinking, a new culture, active self-development of the individual in DL.

The virtual educational space of the subject reflects the relationship of all spheres of personality: intellectual, emotional, semantic, behavioral, etc.

Currently, there are virtually no studies that comprehensively reveal the psychological conditions of distance learning. The very concept of telecommunication computer-educational environment has not yet been properly considered from a psychological standpoint. It is unclear which specialties can be taught in a telecommunications educational environment and in which cases it is impossible or partially possible. Issues of distance education do not yet have a proper psychological justification.

The effectiveness of the learning process using computer technology is possible only if the necessary conditions are created. One of such conditions is the psychological support of students, the purpose of which is to create a favorable psychological climate for distance learning, to assist students in developing an individual style focused on the effective acquisition of knowledge in virtual learning. For teachers, one of the main difficulties is the inability to directly observe the reaction of students to the proposed teaching material, incomplete or incorrect understanding in terms of written feedback between students and teachers. The full-fledged eye contact is violated (during online lectures) or disappears (in correspondence and posting materials on the network), which provides coordination of attention resources and control of perception of information and skills.

The following tasks of psychological support of distance learning are distinguished: 
- $\quad$ study of the environment (communicative individual features of participants);

- $\quad$ study of personal qualities and the level of development of mental properties and qualities;

- $\quad$ study of features of interpersonal relations of participants of distance learning;

- transfer to participants of distance learning of significant information on the discipline;

- creation of the most favorable conditions for the development of the necessary personal qualities of the student and teacher throughout the learning process and their full adaptation to learning conditions;

- $\quad$ provision of an individually differentiated approach to learning, which is based on the psychological characteristics of the student, overcoming the often dominant authoritarian style in traditional teaching.

Among the available approaches are the following areas of psychological research of human learning in cyberspace:

1) study of psychological conditions of successful learning (psychological features, properties necessary for distance learning);

2) based on the study of psychological characteristics of students who successfully study in this system, the creation of a psychological model of an "effective student"; selection of his integrative personal characteristics (indicators of mental development, features of modality of perception of information, characteristics of temperament and personal qualities that are professionally significant and provide successful distance learning);

3) development of methods of remote psychological diagnostics of entrants;

4) psychological analysis of methodical means of learning in the system of distance learning for their psychological adequacy to the goals and objectives, which will lead to the need to develop new means of distance learning;

5) creation of methods and practical psychological tools to solve the problem of identification of students in control testing via the Internet.

Promising are the topics and areas of psychological research related to learning in a virtual environment.

Within the framework of pedagogical psychology there are tasks of group and individual distance learning, development and application of educational programs, models for training of psychological qualities, assessment of the possibility of transferring knowledge and skills acquired in a virtual environment into real life. 
Organizational psychology and psychology of work are mainly interested in the study of new forms of employment and organizational behavior in the Internet, the transformation of professions, the introduction of communicative and organizational principles of network games in the work of professional production, commercial and scientific teams $[2,8]$.

Based on the mentioned psychological aspects of learning in the Internet and human functioning in the virtual environment in general, it can be noted that learning in this space has both the widest range of opportunities and very serious limitations associated with the already fixed risks (Internet and computer dependence, low availability of non-verbal means of communication, stress due to loss of information due to hardware or software and network failures, psychopathology, anonymity, etc.).

3. The integrating role of pathological physiology in the formation of students' communicative, practice-oriented competencies that determine the success of further education at clinical departments and bases.

The integrative role of pathophysiology has further increased in the medical education of the 21 st century. This seems to be due to the deepening understanding of human nature and its diseases, many of which are caused by increasing defects in heredity, constitution, reactivity of the human body associated with deteriorating environmental conditions, and mutations and high aggressiveness of some viruses (HIV, Ebola etc.) [4].

Medicine does not tolerate mediocre attitude towards it: the one who saves human lives must be motivated to acquire knowledge. Also, if one aims to instill in students a love for their profession, it is necessary to begin with basic, theoretical disciplines, in particular, with pathological physiology, which, as a "philosophy of medicine", is a kind of "bridge" between theoretical and practical medicine. The basis of this "vaccination", of course, is motivation. Motivation as the main driving force in human behavior and activities, as well as in the process of forming a future professional. Its formation is an important pedagogical problem/mission, because it is incredibly difficult to get a student to learn the material if he does not understand why he needs it [13].

From the point of view of increasing the role of the motivational component, we will analyze the main aspects of teaching theoretical disciplines. The classical construction of the study of material in theoretical departments takes into account the mandatory accounting of basic knowledge, control of the study of material, presentation of new material and independent work - solving MCQ's, situational problems, filling albums, answers to questions of the teacher. Note that the meaning and content of independent work differ in general theoretical and clinical departments, which, in our opinion, is a possible resource for optimizing students' 
theoretical knowledge. We are convinced that more attention should be paid to the study of the functioning of organs directly on the person (in this case we are talking about student volunteers). It is necessary to introduce more often in practical classes at the department of physiology such important skills as blood pressure measurement, pulse determination, cardiac impulse localization, determination of blood groups, determination of objective indicators characterizing the functional state of the respiratory system, cardiovascular system, excretory system, etc.

We believe that in order to increase the effectiveness of the learning process during the practical session the students should develop the basic prerequisites for clinical thinking clinical diagnosis in most cases is impossible without a harmonious combination of professional and creative diagnostic methods, without the ability to assess all symptoms, laboratory parameters, the presence of comorbid pathology [15]. Therefore, the use of situational tasks and clinical techniques becomes an integral part of seminars and practical classes. In such cases, the student gets the opportunity to "try on" the role of the attending physician and experience the real excitement in formulating the correct diagnosis.

We are sure that at the department of pathophysiology teachers are able to optimize the teaching of material to students so that each student receives integrated data on each function, the work of each organ and organ system in normal conditions, in adapting to environmental factors and pathological processes. The clinical orientation of the educational process at the department of pathophysiology should also take into account the deeper acquisition of knowledge by students in neuropathophysiology, pathophysiological basis of diagnosis, clinical pathophysiology, which will facilitate their further study at clinical departments.

For example, the problem of combined diseases, due to the increasing aggressiveness of the environment and the alternating effects of exogenous environmental factors, is of great medical and social importance, to which students should pay attention in terms of their subsequent study of clinical disciplines. The formation of comorbid pathology is associated with stress overload, information stress, morphogenetic and regulatory disorders of the immune system and other dysfunctions [13]. Comorbidity is one of the most important problems of modern medicine, as the lack of knowledge in this area hinders effective pathogenetically sound treatment, rehabilitation and prevention. The solution to this problem depends on a thorough pathophysiological analysis of the pathogenesis of comorbid pathology. There is a huge lot of data that in the pathogenetic mechanisms of such different diseases schizophrenia, thyroid disease, diabetes, rheumatoid arthritis, rheumatism, atherosclerosis etc. - in addition to the main, one there are identical immune dysfunctions. Therefore, it is 
necessary to further deepen students' knowledge of general pathophysiology, to give clear ideas about the etiology, pathogenesis, reactivity and resistance of the organism, the role of heredity, constitution, mechanisms of action of regulatory systems.

Thus, if students, in addition to the acquired theoretical knowledge, consolidate it while performing practical skills, the degree of assimilation of specific material will be much higher. At the same time, the flow of information coming to each student from different sensory systems increases, new conditioned reflexes are formed, memory and memory processes are activated, and - most importantly - logical-abstract thinking, which is essential for successful senior education, is improved. In our opinion, continuity and integration of teaching of all disciplines "horizontally" and "vertically" will also contribute to better knowledge acquisition.

Knowledge of pathological physiology for the first time reveals to many students a scientific, dialectically sound idea of the role of environmental factors, disturbed ecology, climate change, social and living conditions in the development of pathology. At the same time, we form an understanding of the body's adaptive and compensatory resources, which can delay the severe consequences of the disease, but these resources are not infinite: they can be depleted, and then the disease ends in a lethal outcome [16]. That is why it is necessary to develop a preventive direction in medicine. Even A.A. Bogomolets and his students showed that low connective tissue reactivity is usually associated with a more severe course of the disease, slow wound healing and delayed formation of a "granulation" shaft around damaged tissues, slowed bone healing after fractures, and finally decreased immunity, increased sensitivity to infection due to impaired function of antibody-generating lymphocytes [3].

One of the promising areas of development of methods of teaching theoretical and clinical disciplines is the introduction and widespread use of multimedia teaching aids, which will create a "cumulative effect" of the simultaneous presentation of information from different sources. The presence of a game component in the process of learning will contribute to the formation of a multi-stage vision of the scientific picture of wildlife, polycentrism in the biological worldview and the formation of a holistic picture of the human body in normal and pathology [1].

Promising, in our opinion, is the development of multimedia tools for interactive learning, involving a diverse presentation of information with the possibility of self-control and self-analysis. This sphere of use of computer equipment in our conditions is applied too utilitarian. Therefore, it is necessary to develop multimedia encyclopedias and role-playing games that would fully correspond to the initial program of the theoretical and/or clinical discipline. At the same time, two main tasks are solved: the quality of teaching educational 
material is improved and the efficiency of students' acquisition of knowledge with this type of information provision is significantly increased.

Note that at ONMedU General and Clinical Pathological Physiology Department a significant amount of work in this direction has been underway for two years. Students are fully provided with all necessary sources of knowledge: they have time-tested and latest textbooks, access to the electronic library of the university, the ability to find any needed article on the Internet, numerous manuals written at the department, which can be viewed immediately before the lesson to consolidate the learning material [15]. Nevertheless, the value of any higher education institution is in its teachers - the experienced and highly professional lecturers of the department who are able to "ignite" the audience. They convey the essence of the taught material to the listeners in an interesting and vivid oratorical manner, so that students can figuratively imagine a pathological process that takes place not in an abstract "organism" but in a completely animated patient, if only in their imagination.

Another aspect of the problem is the publication of textbooks for students. The employees of our departments have also been working on this for a long time, which has resulted in the writing of a number of textbooks and manuals on physiology, pathological physiology, therapy and surgery. The advantages of textbooks written by the staff of the departments are their adaptation to the needs of students, taking into account the peculiarities of teaching theoretical and clinical disciplines in each higher education institution, as well as the comprehensive presentation of educational material, despite possible accents in its teaching. In our opinion, the publication of educational literature on various medical specialties is also a promising means of effective acquisition and consolidation of knowledge by future doctors.

We are convinced that the optimization and improvement of the educational process in medical universities is to draw students' attention to the problems that the medical community is dealing with on a daily basis today.

The norms of standardization of diagnostics, treatment, prevention of various pathologies accepted today cannot and should not exclude the individual approach to treatment of the patient taking into account his age, gender, heredity, the constitution, reactivity, disease development stage. This knowledge is provided by a course in general and clinical pathophysiology, which is improved and deepened at all stages of the development of medical science.

\section{Conclusions}


1. In connection with the ideas of individualized and developmental learning, the use of psychological capabilities of learning tools in the virtual environment brings both pedagogy and psychology to a new level of understanding the mediation of mental, creative, communicative and executive learning and learning activities.

2. The use of distance learning helps the students to acquire skills of independent work, creates comfortable conditions for creativity, increases the creative and intellectual potential of the student through self-organization, the ability to interact with computer technology and make responsible decisions, creates favorable conditions for individual creative expression in the process of learning, for the development of the student's personality.

3. At the same time, the Internet space is characterized by specifics that can pose potential threats to the success of learning in it.

4. Therefore, interaction with psychologists is desirable both at the stage of developing distance learning courses in order to increase their effectiveness, and during its implementation in the event of the above problems.

5. In the future it is planned to study the features of self-esteem and job satisfaction of teachers in the process of distance learning in comparison with traditional learning.

6. We see success in systematic methodical work with students, the implementation of which will give the opportunity to cause and increase their motivation to learn. We are sure that the constant rapprochement of teaching theoretical and clinical disciplines, bringing education closer to a particular patient will help optimize the acquisition of theoretical knowledge by students, will lead to better mastery of clinical disciplines.

\section{References}

1. Artyomenko V.V., Vastyanov R.S., Myastkivska I.V., Zaitsev A.S. Tutoring in the process of integrative approach in the innovation-simulation method of teaching medical students. Odessa Medical Journal. 2016; 3 (155): 59-65 [In Ukrainian].

2. Bagdasarova H.A., Chmykhova Ye.V., Bogdanov I.V. Psychological aspects of distance education. Innovations in education. 2003; 5: 78-90 [In Russian].

3. Bogomolets A.A. The value of the body's reactivity in matters of rhehabilitation therapy. Med. J. 1947; 16: 21-43 [In Russian].

4. Gozhenko A.I. Basics of building a theory of disease. Odessa : Phenix, 2015: 84 [In Russian].

5. Kazakov V.N., Klimovitsky V.G., Vladzimirsky A.V. Distance learning in medicine. Donetsk : OOO "Nord", 2005: 98 [In Russian] 
6. Kotiuzhynska S.H., Shmakova I.P., Goncharova L.V. Distance education in medicine: advantages and disadvantages. Achievements of clinical and experimental medicine. 2021; 1: 147-151 [In Russian].

7. Kushch O.H., Omelianchyk V.M., Bessarab H.I., Zhernova N.P., Stepanova N.V., Tykhonovska M.A., Morozova O.V., Sukhomlinova I.Ye. Distance learning in the system of medical education. Medical Education. 2017; 4: 85-89 [In Russian].

8. Lukashenko I., Lutsenko O. Psychological aspects of learning in virtual space. Visnik V.N. Karazin Kharkiv National University, A Series of Psychology. 2016; 60: 40-43 [In Russian].

9. Polyasny V.A., Godlevsky L.S., Vastyanov R.S., Kresyun N.V. Distance learning in the medical education system. Odessa : Odessa National Medical University. 2015: 17 [In Russian].

10. Polyasny V.A., Godlevsky L.S., Vastyanov R.S., Kresyun N.V. Application of the virtual instrumentation program "LabVIEW" in medical practice. Odessa : Odessa National Medical University. 2015: 42 [In Russian].

11. Stoyanov O.M., Vastyanov R.S., Muratova T.M., Dobrovolsky V.V. Innovative comprehensive teaching of neuroscience issues to improve the professional education of neurologists. Integrative Anthropology. 2015; 2 (26): 64-69[In Ukrainian].

12. Vastyanov R.S., Savitsky I.V., Levchenko Ye.M., Ostapenko I.O. The prevailing role of motivation in teaching students at the Department of General and Clinical Pathological Physiology of the Odessa National Medical University. Adv. of Biology and Medicine. 2017; 1: 53-57 [In Russian].

13. Vastyanov R.S., Gurkalova I.P., Babyi V.P., Kuzmenko I.A. Prospects for the development and improvement of teaching pathological physiology in medical universities. Experimental and Clinical Medicine. 2016; 2 (71): 31-35 [In Russian].

14. Vastyanov R.S., Stoyanov O.M., Dzygal O.F., Savitsky I.V., Demidov V.M., Levchenko Ye.M., Onufrienko O.V., Ostapenko I.O. Integration of teaching theoretical and clinical disciplines as one of the factors of the effectiveness of assimilation of knowledge by students of a medical university. Journal of Education, Health and Sport. 2017; 7 (3): 745-758

15. Vastyanov R.S., Savitsky I.V., Levchenko Ye.M., Dzygal O.F. Problems and prospects of teaching foreign students at a medical university. Professional education: problems and prospects. Kyiv. 2017; 12: 14-18 [In Russian].

16. Yakimenko Ye.A., Vastyanov R.S., Gurkalova I.P., Zakatova L.V., Antipova N.N., Tbileli V.V. Pathogenetic mechanisms of comorbid pathology in ankylosing spondylitis 
(ankylosing spondylitis). Experimental and Clinical Medicine. 2016. 2 (71): 237-241 [In Russian]. 